\title{
Incomplete Contracts and Investment: A Study of Land Tenancy in Pakistan
}

\author{
Hanan G. Jacoby* Ghazala Mansuri*
}

October 2002

\begin{abstract}
When contracts are incomplete, relationship specific investments may be underprovided due to the threat of opportunism or 'holdup'. This paper finds evidence of a holdup problem in rural Pakistan. Land specific investment is lower on leased plots than on owned plots cultivated by the same household, even after correcting for the effects of adverse selection in the leasing market. Greater security of tenure is also found to increase investment on leased plots. Differences in tenure security appear to be largely driven by heterogeneity across landlords in their willingness to commit to long-term relationships, suggesting that some landlords value reputation more than others. These findings have implications for both land and tenancy reform.
\end{abstract}

${ }^{*}$ Development Research Group, The World Bank. Contact Information: Jacoby: e-mail: hjacoby@worldbank.org; Mansuri: e-mail: gmansuri@worldbank.org. 


\section{Introduction}

Relationship specific investments are important in a wide variety of economic transactions. As has long been recognized, when contracts are incomplete, ${ }^{1}$ specific investments may be undersupplied due to opportunism on the part of the noninvesting party. The so-called 'holdup' problem arises because the noninvesting party can use the threat of not trading to appropriate some of the returns on the investment. This observation underlies a number of prominent theories of institutions, in which particular organizational structures, such as firms or governments, are rationalized as means of mitigating opportunism in the presence of specific investments. ${ }^{2}$

Despite the centrality of the holdup problem in economics, there is remarkably little direct evidence on its empirical importance. ${ }^{3}$ This paper begins to fill this lacuna by examining the relationship between land-specific investments and land tenancy in rural Pakistan. Our basic question is whether farmers invest more in their own land than they do in land that they lease, either on fixed rent or under share-tenancy. If landlords cannot credibly commit to long-term contracts, then certain types of land specific investment will be underprovided by tenants, ${ }^{4}$ whereas investment in owned land is obviously immune to holdup. ${ }^{5}$

This is not the first paper to compare farming practices on tenanted and owned land, but it is the first paper of its type to study investment behavior. Seminal work by Bell (1977), followed by Shaban (1987), is concerned with static efficiency; i.e., with moral hazard in current production effort that can arise in share-tenancy. Our approach, by

\footnotetext{
${ }^{1}$ The notion of contractual 'incompleteness' is still viewed as somewhat ad hoc (see Tirole, 1999; Hart and Moore, 1999). We follow the recent literature by saying that a contract is incomplete if there are limitations on the parties' ability to forsee contingencies, to write contracts (i.e., delineate the set of all possible trades in advance), and to enforce them. In an earlier literature these came under the rubric of transactions costs.

${ }^{2}$ See, e.g., Klein, Crawford, and Alchian, 1978; Grossman and Hart, 1986; Hart and Moore, 1990, Williamson, 1975; North and Weingast, 1989.

${ }^{3}$ Joskow (1987) finds that longer term contracts are more common as the degree of relationship specific investment increases, but in a context where long-term contracting is feasible. His paper does not examine the investment decision conditional on contractual form.

${ }^{4}$ Banerjee, et al. (2002) also emphasize contractual incompleteness in their discussion of the effects of tenancy reform on investment incentives in India. However, since they only have (district-level) data on yields, it is not possible for them to separate the investment channel from other effects of tenancy reform in their empirical work.

${ }^{5}$ This is actually not so obvious because land ownership may not be secure. Potential expropriation of land by the state or powerful individuals may dampen investment incentives on owned land (see Jacoby, $\mathrm{Li}$, and Rozelle, 2002). In rural Pakistan, land ownership is, in general, clearly established and the risk of expropriation is negligible.
} 
contrast, is to examine the use of an input, farmyard manure, that enhances productivity over more than one agricultural season. While manuring improves soil quality over an extended period, it is an extremely labor intensive activity, one that, in rural Pakistan, is virtually never entrusted to a hired worker. Thus, manuring is for all practical purposes a non-contractible investment. Whether manure will be under-applied on tenanted land relative to owned land depends on the extent to which landlords can commit to rewarding the tenant for his investment. In a world of no commitment, tenants will apply manure only to the point were the marginal return in the current period (i.e., the period of the contract) equals the shadow price, and this dynamic inefficiency will be common to both share tenants and fixed rent tenants, even though the latter are full residual claimants.

Despite the absence of enforceable long-term contracts, annual tenancy contracts are typically renewed in our setting. Tenants often stay with the same landlord for a number of years, certainly long enough to fully recoup an initial (though not necessarily a recurrent) manuring investment. Yet, there is heterogeneity in the degree of tenure security. As our evidence will show, a large part of this heterogeneity is generated by differences across landlords in their retention policies. This fact allows us to ask whether differences in the degree of commitment lead to differences in investment across tenants. In a world of no commitment, in which all tenants are equally insecure, how long a tenancy has lasted indicates nothing about the incentive of a tenant to invest. The alternative hypothesis, against which we would like to test this null, is that duration of tenancy is a signal of the degree of commitment in a relationship, albeit an imperfect one. Longer durations should therefore be associated with greater investment. ${ }^{6}$

Finally, this paper advances the econometric identification of the behavioral effects of contractual form. Past work has stressed the importance of controlling for unobserved characteristics of the agent so as to avoid the problem of self-selection into different contract types. Thus, for example, tenants may invest less than landowners merely because they are less wealthy. The advantage of looking at land tenancy in India (Bell, 1977; Shaban, 1987)-and, as it happens, in Pakistan-is that a given household will often cultivate two or more plots of land under different contractual arrangements, allowing a comparison of behaviors across plots within the same household. A potential limitation of this identification strategy is that it does not deal with the possibility that the decision to lease out

\footnotetext{
${ }^{6}$ Laffont and Mattousi (1995) find that longer duration share contracts are associated with higher farm output in Tunisia. However, because they do not examine investment directly, nor (crucially) allow contract duration to affect output of fixed renters, one cannot use their results to distinguish the holdup problem from moral hazard in effort. Their empirical approach also makes more restrictive assumptions than ours in dealing with the endogeneity issues.
} 
a plot, or to lease it out under a fixed rent versus a sharecropping contract, may depend on the unobserved attributes of the plot, such as would be the case if there is adverse selection in the leasing market. We use instrumental variables to address this endogeneity problem; in particular, using information on the owner of each cultivated plot, which we have even if the plot is leased. ${ }^{7}$

The next section of the paper provides the context for our study and sets out a simple two-period model of tenancy, moral hazard, and land-specific investment. Section 3 describes the estimation strategy, develops the identification argument, and provides evidence on the determinants of tenancy duration. The main empirical results are reported in section 4 , followed by conclusions in section 5 .

\section{Tenancy and Land Specific Investment}

\subsection{Data and context}

Land inequality is pervasive in Pakistan and, as a result, land lease markets are very active. In the latest agricultural census (2000), about a third of total cultivated area was tenant operated, mostly (roughly two-thirds) under crop-sharing arrangements and the remainder under fixed rent. Although land and tenancy reforms have been attempted at various times, they have largely been ineffectual, leaving tenant cultivators with little legal recourse in the event of eviction. Nevertheless, anecdotal evidence suggests that, partly out of fear of future reforms, landlords prefer short-term (seasonal or annual) tenancy contracts.

Our empirical analysis draws upon a new nationally representative rural household survey. The Pakistan Rural Household Survey (PRHS), which was completed in late 2001, collected data from about 2,800 households sampled across 17 districts and 150 villages. Roughly 60 percent of the households surveyed were farm households and a considerable fraction of these operated multiple plots. The survey was designed to provide detailed information at the plot level on land characteristics (soil type, irrigation, and so forth), land tenure (including characteristics of tenants and owners and details of the contracts), and production activities. These data were collected for the two main agricultural seasons, kharif (May-November) and rabi (November-May). The main cash crops, cotton, rice,

\footnotetext{
${ }^{7}$ Besley (1995) follows a related household fixed effects instrumental variables strategy in his study of land-specific investment in Ghana. His paper examines the impact of ownership rights, however, rather than of contractual form.
} 
and sugarcane, are grown in kharif, while the main food crop, wheat, is grown in rabi.

To provide evidence on the holdup problem, we want to focus on an activity that is, in the first place, at least partly an investment. Moreover, we would like this investment to be relationship specific and noncontractible. Last, but not least, it must be relatively easy to measure. Farmyard manure (FYM) meets all of these criteria.

FYM, composed largely of cattle dung, provides variable amounts of the three principal soil nutrients, nitrogen, phosphorous, and potassium. Equally, if not more, important than its role as a nutrient source, FYM improves the quality of the soil by increasing aeration, water retention, structure, and ability to retain nutrients (Government of Pakistan, 1997; Gaur, 1992). Further, these benefits of FYM are long-lasting. ${ }^{8}$ Extended field trials in India cited by Gaur (1992) show that the marginal effects of FYM on grain yields persist for at least three years following the initial application. ${ }^{9}$ Chemical fertilizers, meanwhile, are used extensively in Pakistan, but they leach from the soil relatively quickly and hence their productivity effects are essentially limited to the season of application.

Because FYM, once applied and incorporated into the soil, is not portable, it is a relationship specific investment in the purest sense. By contrast, investments like experimentation with new farming techniques or seed varieties, which have an aspect of general human capital, can be transferred, at least in part, to another landlord-tenant relationship. Still, there are other, larger scale, purely specific investments that farmers undertake in rural Pakistan, such as constructing irrigation and drainage canals, clearing land, and digging wells. However, these fixed investments are, for the most part, contractible; the tenant or some other party can be paid to do them for the landlord. It is, to be sure, an interesting question as to whether contractible investment is underprovided on tenanted land, but it is not one that speaks directly to the holdup problem.

The attraction of FYM, from our perspective, is that it is noncontractible. Farmers rarely purchase FYM, but rather typically collect it as a by-product of their own livestock, load it onto carts or donkeys, transport it to the plot and then spread and incorporated it into the soil. ${ }^{10}$ This process is extremely labor intensive and thus costly to monitor. The extent and quality of FYM application is also not easily verified or observed ex-post,

\footnotetext{
${ }^{8}$ This feature of FYM has been exploited by Jacoby, Li, and Rozelle (2002) in their study of the incentive effects of land expropriation in rural China. Besley (1995) also includes manuring among the investments he examines.

${ }^{9}$ The marginal effect of FYM in succeeding cropping seasons averaged $50-63 \%$ of the effect in the inital season over the three years of the experiments.

${ }^{10}$ Recommended quantities of FYM vary greatly by crop-at the high end, 10-15 cartloads (8000-12000 $\mathrm{kg}$ ) for an acre of sugarcane, and even more for vegetables (Government of Pakistan, 1997).
} 
since weather and other sources of exogenous uncertainty make it difficult to extract this information from realized output alone.

Direct evidence on the noncontractibility of FYM application can be found in the farm wage employment section of the PRHS, where agricultural jobs held over the past year are enumerated by task. A miniscule 0.08 percent of all agricultural wage labor days fall under the category "collecting/spreading farmyard manure". ${ }^{11}$ By way of comparison, about 7 percent of labor days are classified as "weeding", another seemingly hard to monitor task, whereas two-thirds of all paid labor days in agriculture are devoted to harvesting various crops. Harvesting work is more readily contractible because productivity per hour is relatively easy to observe. ${ }^{12}$

Noncontractibility in itself does not preclude an efficient level of investment. If the landlord is able to commit fully to retaining the tenant for the duration of the investment, a contract that makes the tenant the residual claimant to the returns on his investment would induce optimal investment. The landlord could then simply remove any surplus accruing to the tenant by appropriately increasing his rent. The classic holdup problem arises only when the investment is noncontractible and the landlord is unable to commit. The landlord stands to gain, in this case, by renegotiating the contract terms or contract renewal ex-post. The tenant, aware of this potential for opportunism on the part of the landlord, knows that he will not recoup all fruits of his investment. It is thus privately optimal for the tenant to underinvest. The remainder of this section provides a simple model to formalize this intuition.

\subsection{Land specific investment under full commitment}

To derive implications that we can take to the data, we incorporate investment into a standard limited liability model of land tenancy. ${ }^{13}$ Each landlord owns a single unit of land that he cannot self-cultivate and therefore must give over on lease to one out of a large population of tenants. The tenant is the sole provider of current production effort

\footnotetext{
${ }^{11}$ We do not have information from the survey that would allow us to compute the proportion of family labor used for this task. However, data from northeast China, which has an agricultural technology not disimilar from that of rural Pakistan, indicates that 8 percent of annual family farm labor goes into FYM application (Jacoby, Li, and Rozelle, 2002).

${ }^{12}$ Indeed, according to the data, harvesting jobs are nearly twice as likely as weeding jobs to pay piece rates, which rely on directly observing output or effort.

${ }^{13}$ Papers that have modelled tenancy along these lines include Shetty (1988), Basu (1992), and Mookherjee (1997), to name a few.
} 
and investment, ${ }^{14}$ but his actions are unobservable to the landlord. Thus, both effort and investment are noncontractible.

The investment we consider in this paper is recurrent, but we strip the problem down to essentials by focusing on a two-period model. Investment, $m \in(\underline{m}, \bar{m})$, where $\bar{m}$ $>\underline{m} \geqslant 0$, takes place only in the first period, but yields returns in both periods. Because of depreciation, the $m$ available in the second period will be less than in the first. However, we ignore depreciation for simplicity; given our assumptions on technology and costs, this will make no substantive difference to our results.

Effort, $e \in(\underline{e}, \bar{e})$ where $\bar{e}>\underline{e} \geqslant 0$, is undertaken in both periods. Output, $Y \in(0,1)$ is stochastic and has a cdf given by $G(Y)$ that is twice continuously differentiable. We impose the monotonic likelihood ratio property (see, e.g., Laffont and Mortimort, 2002), which says that an increase in either effort or investment increases mean output; i.e., $G_{e}(Y \mid e, m), G_{m}(Y \mid e, m) \leq 0$. To allow for precise predictions, we also impose separability between effort and investment in production, $G_{e m}(Y \mid e, m)=0$, which in our context is unlikely to be a bad approximation.

The tenant incurs a private cost for each action, $c(e)$ and $q(m)$. Both cost functions are twice continuously differentiable, increasing and convex in $e$ and $m$ and $c(0)=q(0)=$ 0 . For technical convenience, these costs functions are also assumed separable from one another. ${ }^{15}$

We take the landlord and tenant to be risk-neutral and we ignore discounting. Since both effort and investment are unobservable to the landlord, the tenant must be rewarded on the basis of a noisy signal, namely output. We consider a linear payoff function for the tenant of the form $s Y-r$, where $r$ is a fixed payment, rent, that can be either positive or negative and $s$ is the output share of the tenant. Tenants have an exogenously given per period outside opportunity cost, $\bar{v}$. A tenant's wealth, prior to contracting, is $w$, and there is a limited liability constraint that ensures that the tenant's payoff is non-negative in all states of nature.

We first consider the case where the landlord can fully commit to a two period contract with the tenant. In this case, the optimal contract maximizes the landlord's expected

\footnotetext{
${ }^{14}$ By contrast, in a model of dual moral hazard, such as Eswaran and Kotwal (1985), the landlord also provides an unverifiable input, such as managerial ability. Although we ignore such complications, allowing a third input of this type should not change the basic story insofar as investment incentives are concerned.

${ }^{15}$ With nonseparability, the model would have to be solved recursively starting from the second period. To the extent that the cost of these two activities interact, in reality, they are likely to be substitutes. That is, higher current production effort would tend to raise the marginal cost of investment effort, and vice versa.
} 
payoff:

$$
\max _{e, m, \alpha, r} V_{L}=2\left[E(Y \mid e, m)-\int_{0}^{1}(s Y-r) g(y \mid e, m) d Y\right]
$$

subject to:

(PC) The tenant's participation constraint requires that the tenant's payoff $V_{T}$ be at least as large as his outside option $2 \bar{v}$. That is,

$$
V_{T}=2\left[\int_{0}^{1}(s Y-r) g(y \mid e, m) d Y-c(e)-\frac{1}{2} q(m)\right] \geq 2 \bar{v}
$$

(LLC) The limited liability constraint requires that in each of the two periods, $s Y-r \geq$ $-\frac{w}{2}$. At $Y=0$ this condition implies $r \leq \frac{w}{2}$ and at $Y=1$ it implies $r \leq s+\frac{w}{2}$.

(ICC) The incentive compatibility constraints require that the tenant's choice of $e$ and $m$ maximize $V_{T}$. The first-order conditions are

$$
-s \int_{0}^{1} G_{e}(Y \mid e, m) d y=c_{e}(e) \quad \text { and } \quad-2 s \int_{0}^{1} G_{m}(Y \mid e, m) d y=q_{m}(m)
$$

The total expected surplus from the contract is the sum of the payoffs of the landlord and tenant, or $2[E(Y \mid e, m)-c(e)]-q(m)$. The first order conditions to maximize the total surplus are

$$
-\int_{0}^{1} G_{e}(Y \mid e, m) d y=c_{e}(e) \quad \text { and } \quad-2 \int_{0}^{1} G_{m}(Y \mid e, m) d y=s_{m}(m)
$$

Solving these two conditions yields the first-best, which is the effort and investment levels that would be chosen by an owner-cultivator.

From the tenant's ICC, it is clear that the first-best effort and investment levels are achieved only when $s=1$, that is, when the lease is given on fixed rent. In essence, a landlord who can fully commit can 'sell' the property rights on land to the tenant for the duration of the contract. The tenant as residual claimant is fully incentivized and both moral hazard problems consequently disappear. However, it can be shown that 
the landlord will only offer a fixed rent contract to those tenants with sufficiently high wealth. ${ }^{16}$

If the tenant is sufficiently poor, then the landlord faces a tradeoff between production efficiency and surplus extraction; as a result, he may offer the tenant a share contract ( $0<s<1$ ). Crop sharing gives rise to the familiar 'Marshallian' inefficiency, in which current production effort and, in our model, investment are provided below their first best level.

\subsection{Tenure Insecurity and Investment}

Consider now the polar opposite case in which the landlord can only commit to a oneperiod contract and can costlessly employ another tenant in the second period. The tenant's PC is then

$$
V_{T}=\left[\int_{0}^{1}(s Y-r) g(y \mid e, m) d Y-c(e)-q(m)\right] \geq \bar{v}
$$

and the first order conditions for $e$ and $m$ become

$$
-s \int_{0}^{1} G_{e}(Y \mid e, m) d y=c_{e}(e) \text { and }-s \int_{0}^{1} G_{m}(Y \mid e, m) d y=q_{m}(m)
$$

Comparing conditions 3 and 5, it is clear that a fixed rent tenant will still supply the first-best level of effort, but not the first-best level of investment. With no commitment, the marginal return on investment is half as large as in the full commitment case. Thus, making the tenant the residual claimant does not eliminate the dynamic inefficiency due to tenure insecurity. The situation is equivalent in the case of a share contract, except that the marginal return on investment is even lower (by a factor of $s$ ), as is the incentive to provide current production effort.

These observations can be summarized in our main proposition.

Proposition 1 If investment is noncontractible and the landlord cannot commit to a tenancy contract that lasts at least as long as the duration of the investment, then the

\footnotetext{
${ }^{16}$ In particular, the landlord will choose $r^{*}=\left[E(Y)-c\left(e^{*}\right)\right]-\frac{1}{2} q\left(m^{*}\right)-\bar{v}$, where $\left(e^{*}, m^{*}\right)$ represent the first-best, provided that $w \geq 2 r^{*}$ in respect of the LLC.
} 
tenant will undersupply land specific investment, even if the contract provides very high powered incentives (i.e., fixed rent).

In practice, this hold-up problem may be mitigated by reputational effects. Specifically, a landlord may be reluctant to milk his reputation by reneging on his tenant, realizing that if he does so he will be 'punished' by never getting optimal investment on his land. Of course, reputational equilibria are sensitive to a number of assumptions, such as the extent of information costs, on which we need not dwell (see, e.g., Kreps, 1990). The point is that the existence of reputational heterogeneity provides us with an additional testable implication. Returning to the model, assume that the tenant, knowing his landlord's reputation, believes his contract will be renewed in the second period with probability $\theta$. Full commitment can then be interpreted as the case where $\theta=1$, and no commitment as the case where $\theta=0$. Clearly, $\theta>0$ will increase investment relative to the no commitment case. We thus have

Proposition 2 As the degree of tenure uncertainty increases, the tenant will reduce his land specific investment.

There are other potential sources of heterogeneity in tenure security besides landlords' retention policies. Tenants may have different search or moving costs or face different distributions of outside opportunities. In these cases, we may find that some tenants underinvest relative to others even if all landlords can fully commit to long term contracts. It is, in effect, the tenant here who cannot commit to staying long enough to recoup his investment. However, in the environment that we study, heterogeneity in turnover rates induced by tenant characteristics is unlikely to be of great importance. We return to this issue in the next section.

\section{Econometric Framework}

\subsection{Basic specification and identification}

The basic regression model for FYM use, $M_{c i}$, by cultivator $c$ on plot $i$ is

$$
M_{c i}=\alpha L_{c i}+\beta \prime X_{c i}+\nu_{c}+\varepsilon_{c i}
$$

where $L_{c i}$ is an indicator of whether the plot is leased and $X_{c i}$ is a vector of exogenous plot characteristics. The error term $\nu_{c}$ captures all unobserved factors common to a given 
cultivator that determine input use; e.g., prices, wealth, access to credit, risk aversion and the discount rate, farming knowledge, average land quality, and, importantly, the household's available stock of FYM and other farm assets. Meanwhile $\varepsilon_{c i}$ contains plotspecific unobservables, such as land quality, that are not captured by the variables in $X_{c i} \cdot{ }^{17}$

To deal with the possibility that $\nu_{c}$ is correlated with contractual choice, namely with $L_{c i}$, we follow earlier work in the literature by restricting our attention to owner-cumtenant households. Suppose, for the sake of exposition, that we have a sample consisting of two-plot households, one plot of which is leased in $\left(L_{c i}=1\right)$ and the other which is owned $\left(L_{c j}=0\right)$. In this case, the first-differences estimator and the fixed effect estimator, the one that we actually use in the empirical work, are numerically identical.

Differencing equation 6 across plots within a household, yields

$$
\Delta M_{c}=\alpha L_{c i}+\beta \prime \Delta X_{c}+\Delta \varepsilon_{c}
$$

where $\Delta$ is the difference operator. The OLS estimate of $\alpha$ from this regression is consistent provided that $E L_{c i} \Delta \varepsilon_{c}=0$. As long as the set of observed plot characteristics $X_{c i}$ is sufficiently rich, this identifying assumption (maintained by Shaban, 1987, among others) is reasonable. However, plot fertility is not easy to assess in survey data. Moreover, unobserved plot fertility could be correlated with leasing choice for two reasons. First, adverse selection may arise when a component of plot fertility is private information to the landowner, in which case less fertile plots would tend to be leased out rather than owner-cultivated. Second, moral hazard on the part of the tenant would have a similar effect if more fertile plots are more sensitive to soil degradation (see Dubois, 2002, for a tenancy model along these lines).

Endogeneity bias induced by the correlation between $L_{c i}$ and $\Delta \varepsilon_{c}$ can be tackled using instrumental variables. However, this requires instruments that are correlated with contractual choice, that are uncorrelated with unobserved attributes of the plot, and, crucially, that vary across plots within the same household. Such variables are typically hard to come by in farm household surveys. In our data set, though, tenant cultivators report the characteristics of their landlord, including among other things his total landholdings. Let $A_{o i}$ denote the total landholdings of the owner of plot $i$, which

\footnotetext{
${ }^{17}$ We eventually also include in the regression an (endogenous) indicator for whether the plot is leased in on fixed rent, as opposed to sharecropped, but since this does not introduce any new econometric issues we defer our discussion of this variable.
} 
for owner-cultivated plots will just be the landholdings of the cultivator himself (i.e., $A_{o j}=A_{c j}$ if $L_{c j}=0$ ). Thus, our principal instrument for $\Delta L_{c}=L_{c i}$ in equation 7 is $\Delta A_{o}=A_{o i}-A_{o j}=A_{o i}-A_{c j}$. Put simply, plots whose owners have relatively more land are more likely to be leased out and less likely to be self-cultivated. Moreover, it is reasonable to argue that the difference in total landholdings between the owner-cumtenant and the landlord of his leased plot is uncorrelated with differences in the unobserved attributes of his owned and leased plots.

We construct additional instruments by interacting $\Delta A_{o}$ with other variables, such as the land endowment of the cultivator $A_{c}$, thus allowing the impact of relative land endowments on the leasing decision to vary by the landholdings of the tenant-cultivator. Note that the direct effect of the cultivator's landowership on his input use has already been removed from equation 7 along with the fixed effect $\nu_{c}$.

\subsection{Security of tenure: Econometric considerations}

Equation 7 assumes that the impact of leasing on investment is the same for all tenants (i.e., a common $\alpha$ ). We now consider heterogeneity in security of tenure. Let $\mu_{o c}$ be a latent variable representing the degree of tenure security, the dual subscripts indicating that this variable is specific to an owner (landlord)-cultivator (tenant) match. In terms of the model in section 2.3, we may think of $\mu$ as the objective probability of contract renewal, in contrast to the subjective (on the part of tenant) probability $\theta$; in other words, $\theta$ is the tenant's prior on $\mu$. For $\mu$ to matter for investment behavior, the tenant's prior must be informative to some extent.

For owner-cultivated plots, on which tenure security is presumably absolute and unvarying, we set $\mu_{o c}=\mu_{c c}=1$ without loss of generality. We also make the innocuous normalization $E\left[\mu_{o c} \mid L_{i c}=1\right]=0$, from which it follows that $E\left[\mu_{o c} L_{i c}\right]=0$. Augmenting equation 7 gives

$$
\Delta M_{c}=\alpha L_{c i}+\beta \prime \Delta X_{c}+\gamma L_{c i} \times \mu_{o c}+\Delta \varepsilon_{c} .
$$

Our null hypothesis is that $\gamma=0$; i.e., tenure security does not influence the tenant's investment on his leased plot vis a vis his owned plot. The alternative hypothesis is that investment incentives are stronger in more secure tenancies, so that $\gamma>0$.

The test requires that we observe $\mu_{o c}$. Fortunately, the ongoing or elapsed duration of a tenancy, $d_{o c}$, is a (noisy) indicator of the underlying insecurity of tenure. To see this, we invoke the Jovanovic (1979) model, in which the hazard rate of job separation in the 
presence of specific investment is a function of elapsed job duration and of match quality. If workers (tenants) have different costs of search and firms (landlords) have different retention policies, then the Jovanovic model generalizes to one in which the hazard rate also depends on these additional exogenous sources of turnover. Since the hazard rate (which is one minus the contract renewal probability) uniquely defines the distribution of tenancy duration, we may write $\log \left(d_{o c}\right)=E\left[\log \left(d_{o c}\right) \mid \mu_{o c}\right]+\xi_{o c}$, where $\xi_{o c}$ is random 'luck'. Linearizing the conditional expectation delivers ${ }^{18}$

$$
\log \left(d_{o c}\right)=\mu_{o c}+\xi_{o c}
$$

Equation 9 suggests putting (demeaned) log duration interacted with the dummy variable $L_{c i}$ into equation 8 as a proxy for $L_{c i} \times \mu_{o c}$. It also implies that doing so would lead to an errors-in-variables problem, because of $\xi_{o c}$. Since the resulting estimate of $\gamma$ is biased toward zero, we will tend to find weaker evidence against the null (that $\gamma=0$ ) than if we could observe $\mu_{o c}$ directly. Of course, this is a moot point if we actually do end up rejecting the null. Meanwhile, since $E\left[\mu_{o c} L_{i c}\right]=0$, the estimate of $\alpha$ is still unbiased regardless of the extent of measurement error in $\mu_{o c}$.

\subsection{Security of tenure: Evidence from landlords}

For our test of the tenure security hypothesis to have power, there must be a reasonable amount of variation in tenancy duration. But variation in $d_{o c}$ does not necessarily imply variation in $\mu_{o c}$, or in $\theta$ for that matter. To see why, take the case where $\theta$, the subjective probability of retention, does not vary across tenants. Since actual contract renewal is a stochastic process, we would still observe a nondegenerate distribution of elapsed tenancy durations, but no relationship between duration and investment.

Before proceeding to the main results of the paper, it is worth assessing the extent to which tenancy duration reflects heterogeneity in objective factors like tenant mobility and landlord behavior (which determine $\mu_{o c}$ ). ${ }^{19}$ We do so using data collected from the landlords in our sample. For each plot that was leased out, the survey asks the plot owner about the characteristics of the tenant, including his principal assets, and about the duration of the tenancy. For reasons that will become apparent shortly, we focus only on those landlords who report at least two leased plots, which gives us a sample of 345

\footnotetext{
${ }^{18}$ Notice that if elapsed durations are distributed as a Weibull, then the linear approximation is exact.

${ }^{19}$ Match quality, which by definition is not specific to the landlord or to the tenant, cannot be distinguished from the error term $\xi_{o c}$.
} 
tenanted plots owned by 127 landlords. The median elapsed tenure in this sample is 4 years and the mean is about 6 years.

Column (1) of Table 1 reports a regression of log duration on an array of tenant, landlord, and plot characteristics, and on geographical dummies for each of the 18 tehsil (administrative units below a district). Somewhat less than a third of the total variance in $\log$ (duration) is explained by these covariates. Tenants with larger land holdings appear to be less mobile, staying with a given landlord longer. But tenants' ownership of a tubewell or a tractor/plow has no effect on duration, nor do any of the landlord asset variables.

The regression in the second column of Table 1 includes landlord fixed effects. All the landlord characteristics and tehsil dummies consequently drop out. Remarkably, this regression explains almost 80 percent of the variance in log duration. This means that a landlord-specific unobservable, which is uncorrelated with landlord assets, accounts for at least half of the variation in tenancy durations in our sample. In fact, if we drop all the other covariates, the landlord fixed effects by themselves explain 74 percent of the variance.

Evidently, a large portion of the variation in $\mu_{o c}$ consists of heterogeneity in the behavior of landlords toward all their tenants taken as a group. This suggests that some are able to acquire reputations as 'good' landlords who do not opportunistically evict their tenants. The significance of this findings is that, not only can we use duration data to test proposition 2 , but we can interpret any tenure security effect as arising largely from landlord commitment problems.

\section{Empirical Results}

\subsection{The leasing effect}

Starting from the nearly 2400 plots on which there was at least some cultivation during the 2000-01 agricultural year, we drop those of households cultivating a single plot. As shown in Table 2, this leaves us with 1508 plots operated by 593 households for the fixed effects analysis of FYM use. Of these plots, 477 are cultivated by 185 owner-cumtenant households; i.e., households with at least one owner-cultivated plot and one leased plot. It is exclusively these plots that will identify any contracting effect. Since we want to control for a number of plot characteristics as well, we retain the remaining 1,031 plots to maximize the efficiency of the estimates. The 337 leased plots in this subsample also 
help in estimating the tenancy duration effect.

Before proceeding, a point about our measure of FYM, which is in kilograms used over the year per cultivated acre of the plot. Although all plots in our sample had some cultivation during the year, parts of some plots were left fallow or in some cases a whole plot was uncultivated during one season (usually for lack of irrigation water rather than to rejuvenate the soil). In principle, farmers might apply FYM to fallow areas for the benefit of future crops, though, given that the highest return on manuring is realized in the season of application, this strategy seems inefficient. Nevertheless, to check whether such behavior varies systematically by tenancy status, we experimented with FYM use scaled by the total area of the plot, regardless of cultivation. Since the estimated leasing effects differ only at the third decimal place across these two ways of defining the dependent variable, we just report the results based on FYM per cultivated acre in this paper.

The descriptive statistics in Table 2 foreshadow some key results. Among the ownercum-tenant households, owned plots receive nearly twice as much FYM on average as leased plots, and owned plots are considerably more likely to receive any FYM in the first place. Furthermore, there is no discernible difference in FYM use between sharecropped plots and those leased in under a fixed rental arrangement, although the use rate is somewhat lower on rented plots. While these findings are in line with the predictions of our holdup model, it is premature to draw conclusions based on simple mean comparisons.

Two additional features of the data on FYM use emerge from Table 2, each with implications for our estimation procedure. First, the data are heavily censored at zero; almost two-thirds of plots receive no FYM (partly this is attributable to the carryover effect, which may make it uneconomical to apply every year). Second, for those plots on which FYM is applied, there is a great range of variation in the amount per acre. We thus experimented with various transformations of the dependent variable. Among those that can handle zero values, we found that a simple one, $\log (M+k)$, works reasonably well. ${ }^{20}$ Unfortunately, in the presence of zeros, there is no way to let $k$ be a free parameter in the estimation, so the choice of $k$ is largely arbitrary (we set it to 0.1 ). ${ }^{21}$ In addition, the estimated coefficients are not invariant to the choice of $k$, which means that these coefficients cannot be used to compute, say, the implied percentage differential in FYM use on leased versus owned plots. Instead of making such quantitative statements, our focus,

\footnotetext{
${ }^{20}$ Compared to the linear model, at least, it gives a vastly lower likelihood value.

${ }^{21}$ We choose $k$ so that it is at least an order of magnitude less than the minimum value of the dependent variable. Maximum likelihood estimation of $k$ would fail, since the log Jacobian of the transformation of $y$ is $-\log (y+k)$. At $y=0$, the optimization algorithm would always try to set $k$ as close to zero as possible.
} 
for now at least, is on hypothesis testing. For this purpose, the logarithmic transformation is perfectly adequate since the $t$-statistics are essentially invariant to the choice of $k{ }^{22}$

All the specifications reported in Table 3 include household fixed effects along with the following plot characteristics: area, location (inside/outside village), access to yearround or seasonal canal irrigation, access to groundwater of varying quality, topography, soil quality, and self-assessed plot value. ${ }^{23}$ Details of these variables and their coefficient estimates for a particular specification are reported in appendix Table A.1. Initially, we assume that leasing choices are uncorrelated with the unobserved attributes of the plot. The leasing coefficient estimate from our basic model in row (1) is negative and highly significant ( $p$-value $<0.0000)$, meaning that, conditional on observed characteristics, a leased plot receives less FYM per acre than an owned plot cultivated by the same household.

To assess the ramifications of severe censoring of FYM use at zero, we use Honore's (1992) fixed effect tobit estimator. While this estimator makes limited distributional assumptions, it does not allow us to treat leasing choices as endogenous conditional on the fixed effect. To get estimates comparable to those in row (1) - i.e., marginal effects - we multiply the fixed effect tobit coefficients and standard errors by one minus the observed censoring rate. ${ }^{24}$ The results in row (2) of Table 3 show that ignoring corner solutions leads us to understate the evidence against the null, but not by very much; the $t$-statistic on the leasing coefficient rises from 5.78 in row (1) to 6.48 in row (2).

Another salient feature of our data is the enormous variation in the size of farm plots in rural Pakistan. The variance of FYM per acre is also much higher on the smaller plots. We therefore depart from the homoskedasticity assumption by allowing $\operatorname{var}\left(\varepsilon_{c i}\right)=\sigma^{2} a_{c i}^{-\eta}$, where $a_{c i}$ is plot area and $\eta$ is estimated along with the other parameters (by maximum likelihood). The results of reestimating specification (1) with $\eta$ free are reported in row (3). The leasing coefficient is basically unchanged, though the standard error is marginally lower. Even though we can reject homoskedasticity $(p$-value $=0.0001)$ and the residual variance does, as expected, decline with plot area (i.e., $\widehat{\eta}>0$ ), heteroskedasticity is not severe enough in this logarithmic specification to make much of a difference. Nonetheless,

\footnotetext{
${ }^{22}$ For example, the $t$-value for the leasing coefficient in row (3) of Table 3 is 5.91. The corresponding $t$-value is 5.92 when $k=0.01$ and 5.93 when $k=0.001$, even though the associated coefficients vary widely in magnitude.

${ }^{23}$ Both owners and tenant cultivators are asked to report plot value in the survey. One might worry that these values partly reflect the extent of past manuring, although this seems quite unlikely given that the effects of FYM are far from permanent. In any event, the exclusion of this variable from the regressions has a negligible impact on the estimates of interest.

${ }^{24}$ Strictly speaking, unless one imposes distributional assumptions, the fixed effect tobit does not yield predicted marginal effects.
} 
we continue to leave $\eta$ unrestricted for the remainder of our estimation.

Next we relax the assumption that the leasing decision is uncorrelated with unobserved plot characteristics. As discussed earlier, one way such a correlation might arise is if plot owners have private information about soil fertility. The impact of adverse selection in the land leasing market on our estimates depends on the relationship between FYM use and unobserved soil fertility. If low fertility plots have a lower return to manuring, then adverse selection will lead to a negative correlation between the leasing dummy and the error term, whereas this correlation will be positive if low fertility plots have a higher return to manuring. In short, the endogeneity bias in the leasing coefficient could go either way.

Row (4) of Table 3, presents an IV version of specification (3). The 12 excluded instruments include assets of the plot owner - the log of total landholdings, a dummy for landholdings exceeding 100 kanals (= 12.5 acres, considered a small holding), a dummy for tractor ownership, and a dummy for tubewell ownership - and interactions of these four variables with each other as well as with the total owned area of the plot cultivator. As reported in Table 3, the explanatory power of these instruments for the leasing choice, conditional on the household fixed effects and the plot characteristics, is high; they also easily pass the overidentification test. ${ }^{25}$ However, the impact of instrumenting on the leasing coefficient is negligible (Wu-Hausman test $p$-value $=0.507)$. This failure to reject exogeneity is especially compelling given the high power of the test. ${ }^{26}$ Aside from the lack of evidence for an adverse selection effect, on the basis of the IV estimates we (still) resoundingly reject the hypothesis $(p$-value $<0.0000)$ that leased and owned plots receive the same amount of FYM.

Since recommended amounts of FYM vary greatly by crop, it is worth asking how much of the leasing effect is due to differences in the crops grown on tenanted versus owner-cultivated plots. Row (5) of Table 3 replicates specification (3) but includes a set of crop composition variables for the 8 most important crops (wheat, rice, cotton, sugarcane, maize, rabi fodder, sorghum fodder, and vegetables). The leasing effect is

\footnotetext{
${ }^{25}$ To be conservative, throughout this paper we use the heteroskedasticity robust version of the overidentification test (see Wooldridge, 1995).

${ }^{26}$ We can quantify this statement using an inverse power function calculation (Andrews, 1989). Suppose, for the sake of argument, that adverse selection biases the leasing coefficient upward, against the null. A one-sided Wu-Hausman test for exogeneity has high power (i.e., a 95 percent chance of rejecting the null at the 5 percent level) if the true difference between the instrumented and uninstrumented leasing coefficient estimates is only 0.99 . So, we can be highly confident that we would have rejected exogeneity if the true leasing coefficient was less than (in magnitude) -0.96. But even a leasing coefficient this small would lead us to reject the null of equal investment across owned and leased plots.
} 
modestly attenuated, but is still 85 percent as large as before. Tenants seem to respond to the investment disincentive, not so much by planting less of those crops that thrive on FYM ${ }^{27}$ but rather by using FYM less intensively on every crop. A caveat is that (notwithstanding the evidence just reported for leasing choices) crop choice may be correlated with unobserved plot attributes. We do not have enough (good) instruments to deal with the endogeneity of all the crop composition variables. Be that as it may, our paramount interest in this paper is on the total investment disincentive of tenancy, and for this purpose crop composition should not be held constant.

\subsection{The tenure security effect}

Having firmly established an investment differential between owned and leased plots on average, we next consider the effect of variation in tenure security across leased plots. Among the 563 tenanted plots in our sample, the median number of years that the same tenant has cultivated the plot is 7, 8 years for share-tenants and 4 years for fixed-rent tenants. Rows (6) and (7) of Table 3 provide strong evidence of a tenure security effect. The negative impact of leasing on FYM use is significantly reduced as tenancy duration increases, whether leasing is treated as exogenous ( $p$-value $=0.0015)$ or as endogenous $(p$-value $=0.0019) .{ }^{28} \quad$ More durable relationships between landlord and tenant, which the evidence in section 3.3 suggests are associated with 'better' landlords, yield greater investment. So, we do not seem to be in a world of no commitment. Meanwhile, the average effect of leasing on investment does not change appreciably after accounting for tenancy duration, remaining strongly significant in both rows (6) and (7).

All of this assumes that the duration of a tenancy is uncorrelated with the unobserved attributes of the plot. But perhaps tenants stay longer on plots of better quality, and, after all, plot quality is not fully observable to us. Unlike the case of the leasing choice, we cannot instrument duration. The results in section 3.3 suggest that this approach would be futile, since they show that landlord assets explain little of the observed variation in tenancy durations. We can, however, check whether our estimates are affected by dropping observable indicators of plot quality from the regression; specifically, irrigation,

\footnotetext{
${ }^{27}$ Rabi fodder seems to be one such crop. On the one hand, it receives a lot of FYM. On the other hand, the proportion of cultivated area devoted to this crop is significantly greater on owned plots than on leased plots farmed by the same household.

${ }^{28}$ Note that the log duration variable is not itself treated as endogenous in the IV specification. However, it enters the regression as an interaction with the leasing dummy, which is endogneous. Thus, to implement the IV estimator, we simply augment the instrument set with interactions between log duration and the original 12 excluded instruments.
} 
topography, soil type, and plot value. If we omit these variables from specification (6), we obtain a leasing coefficient of -1.66 (0.333) and a duration coefficient of 0.769 (0.216), the latter being little more than ten percent higher than its counterpart in Table 3. Given these results, it seems doubtful that a large portion of duration effect can be explained by unobserved plot characteristics.

As we have emphasized, the potential for holdup is present regardless of whether the tenant has taken the land on fixed rent or on a share contract. Although the fixed rent tenant, unlike the sharecropper, is full residual claimant, as long as he cannot be assured of the full return on his land-specific investment, he will also invest less than a plot owner. The final specifications in Table 3 include a dummy for whether the plot is leased on a fixed rent basis. The coefficient on this dummy captures the effect of fixed rental on FYM use over and above the average leasing effect. Thus, if holdup is an issue, we expect the sum of the leasing and fixed rent coefficients to be significantly less than zero. Further, as we have seen, the theory predicts that the fixed rent coefficient will be positive; fixed rent tenants would provide the first-best level of manuring in a world of full commitment, but, regardless of the degree of commitment, share-tenants would always underprovide this investment because of moral hazard.

To help explain the decision to take a plot on fixed rent versus on share, and thus to improve the precision of our IV estimates, we add 6 instruments to our earlier set of 12 (specifically, interactions between two of the plot owner asset variables and three village-level variables: proportion of land sharecropped, proportion of land rented, and gini coefficient for landownership). ${ }^{29}$ But even this augmented instrument set does not explain the fixed rent decision very well, relatively speaking; the $F$-statistic for the excluded instruments in the fixed rent equation is only 27.3, compared to 60.6 in the leasing equation. Nevertheless, whether we use instruments (row (9)) or not (row (8)), we can reject with near certainty the hypothesis that plots leased on fixed rent receive the same amount of investment as owned plots ( $p$-value $=0.0002$ in row $(9) ;<0.0000$ in row $(8)$ ). Far less certain is the comparison between fixed renters and share tenants. The uninstrumented results in row (8) suggest that rented plots actually receive less FYM than sharecropped plots $(p$-value $=0.022)$. After instrumenting, the fixed rent coefficient is practically unchanged but becomes insignificant. If we ignore the endogeneity of leas-

\footnotetext{
${ }^{29}$ The first two of these village level variables are computed directly from the full survey sample, whereas the land gini is based on a census of landownership for the entire population of each village. Since these 6 new instruments hardly add any explanatory power to the first-stage regression for the overall leasing decision, we did not use them in the earlier IV specifications.
} 
ing decisions (as seems justified), and return to the fixed effect tobit estimator discussed earlier, we obtain the results reported in row (10). Here we again find a negative but insignificant fixed rent effect $(p$-value $=0.303)$.

The curious finding that share-tenants do not invest any less than fixed rent tenants might be explained by stepping outside our model and appealing to a monitoring argument. Given moral hazard in current production effort, it pays at the margin for a landlord to be involved in and to supervise his share-tenant's production activities, and sharetenants in Pakistan are usually heavily supervised, either directly by the landlords or by the landlord's hired agents (kamdars). Presumably, because of economies of scope, the landlord's cost of also monitoring investment effort is lower for share tenants than for fixed rent tenants. If this monitoring effect outweighs the moral hazard effect, then we could find share tenants investing more than fixed rent tenants. But this is speculation, and a formal econometric investigation is beyond the purview of this paper. Our main result is that tenants of either type, unequivocally, invest less than owners.

\subsection{Further tests}

One might object to our evidence for a tenure security effect on the grounds that whatever it is that ties the tenant to his landlord could influence not only his FYM use, but his other input decisions as well. What if, for example, landlords use an eviction threat to elicit higher effort on the part of their share-tenants (see, e.g., Banerjee, et al., 2002)? Longer duration tenants might then be precisely those who tend to shirk less. In this case, there may be nothing special about FYM use; any number of current inputs may also be positively associated with tenancy duration.

But eviction threats apply only to share-tenants. Since fixed rent tenants are already providing the first-best level of current inputs, the landlord cannot gain by further incentivizing them with the threat of eviction. Thus, if the so-called tenure security effect in Table 3 is actually generated by eviction threats, it can only be due to variation in the duration of share-tenancies. Under the eviction hypothesis, in other words, if we allow the coefficient on log duration to differ by type of tenancy we should get a coefficient of zero for fixed rent tenants. What we find is just the opposite. Estimating an unconstrained version of specification (8) in Table 3 leads to a log duration coefficient of 0.508 (0.253) for share-tenants and 0.837 (0.416) for fixed-rent tenants, both of which are significantly different from zero, but not from each other $(p$-value $=0.494)$. The same modification of

the fixed effect tobit specification (10) yields identical conclusions. So, it does not appear 
that the positive relationship between FYM use and tenancy duration is being driven by eviction threats. ${ }^{30}$

One could still argue that this relationship is not unique to FYM. In Jovanovic's (1979) model, for example, heterogeneity in match quality determines both job duration and productivity. If long-lived tenant-landlord matches are more productive, then they may also be associated with more intensive use of many inputs. Our final test examines the use of chemical fertilizers. Since these fertilizers have negligible carryover across seasons, their use should not be directly affected by investment incentives and consequently by variation in tenure security. ${ }^{31}$ There are, however, two potential indirect effects. The first is due to interaction in production between chemical fertilizers and FYM. Given that FYM enhances the efficacy of chemical fertilizers, it is not clear whether these two inputs are, on balance, substitutes or complements. If they are strong enough complements (substitutes), then chemical fertilizers would be used more (less) intensively on owned plots and on leased plots with a high degree of tenure security. A second indirect effect is due to share-tenancy. To the extent that sharecroppers provide the second-best level of effort, they may also apply chemical fertilizers less intensively. Note, however, that in most cases fertilizer costs are shared between landlord and tenant at the same rate as they share output. This implies that underuse of chemical fertilizers can occur only through a complementarity of fertilizer use with farming effort. With these complications in the background, we turn now to the evidence.

By far the two most important chemical fertilizers in Pakistan are nitrogen and phosphate (potash is used sparingly). As shown in Table 2, both of these chemicals are applied to more plots in a given year than is FYM, but mean quantities per acre hardly differ across owned and leased plots. Our estimation approach is essentially the same as in Table 3. Since we find no evidence of heteroskedasticity (i.e., $\widehat{\eta}$ is not significantly different from zero) for both nitrogen and phosphate, we impose the restriction $\eta=0$ throughout. Also, for the IV estimation, using the same 18 instruments as in Table 3, we reject the overidentifying restrictions for both fertilizers. To get instruments that pass

\footnotetext{
${ }^{30} \mathrm{An}$ altogether different concern is that owner-cum-tenants are a selective - and, in particular, a behaviorally distinct - sample of the tenant population. Shaban (1987) deals with exactly this issue in testing for static efficiency, but finds no evidence for it. In our case, one would have to argue that both owner-cum-sharecroppers and owner-cum-renters are selective of their populations (all share-tenants and all fixed rent tenants, respectively) in precisely the same way. Moreover, our tenancy duration results do not rely exclusively on owner-cum-tenant households, but rather on a larger sample that includes landless households with more than one leased plot.

${ }^{31}$ One caveat is that leasers may have an incentive to overapply chemical fertilizers relative to owners because they do not fully internalize the damage to soil (see, e.g., Allen and Lueck, 1993).
} 
this test, we drop 8 of the interaction terms from the original set, which gives us, in the case of nitrogen, specification (3) of Table 4. In the case of phosphate, no subset of the original instruments manages to pass the overidentification test, so we do not report any IV results for this fertilizer.

Not a single coefficient associated with the form of tenancy or its duration is statistically significant in Table 4; this includes the specifications that deal with censoring of chemical fertilizer use at zero (rows (2) and (5)) and with the endogeneity of leasing choices (row (3)). Thus, we cannot reject the hypothesis that owned, rented, and sharecropped plots all receive the same amount of nitrogen and phosphate fertilizer per acre. ${ }^{32}$ That there is also no significant association (either positive or negative) between tenancy duration and the use of these chemicals supports our interpretation of duration as a proxy for tenure security and not mainly as a reflection of match quality. Under our interpretation, the degree of tenure security should not directly affect a static input like chemical fertilizer.

\section{Conclusion}

Although the holdup problem lies at the core of incomplete contract theory, its empirical relevance remains an open question. This paper finds striking evidence of a holdup threat in rural Pakistan: Investment is lower on leased land than on owned land cultivated by the same household, even after correcting for the effects of adverse selection in the leasing market. Further corroboration is found in the fact that land taken on fixed rent receives as little, if not less, investment than land taken on a share basis, a result that is inconsistent with an explanation based on static moral hazard.

We also find that security of tenure, and hence the incentive to invest, varies considerably across tenancies. This means that the mere potential for holdup does not necessarily lead to an unravelling of all investment. What is the mechanism for restraining ex-post opportunism? Our data show important differences across landlords in their propensity to retain their tenants, suggesting that some landlords might value reputation more than others. One can imagine an equilibrium in which 'good' landlords, who can credibly commit to not appropriate their tenants' investment returns, coexist with 'bad' landlords on whose land tenants never invest. From the policy perspective, the finding that the degree of commitment varies across tenancies means that there is scope for effective ten-

\footnotetext{
${ }^{32}$ Shaban (1987) obtains similar results for fertilizer use in the ICRISAT villages of India, where costs of purchased inputs are also typically shared between landlord and tenant.
} 
ancy reform. Put differently, if tenure insecurity arises merely from inherent differences in tenant mobility, not from landlord behavior, then legislation binding landlords to long term contracts would do little to encourage investment.

Finally, it is worth asking about the economic significance of underinvestment on tenanted land. Of course, the full extent of the dynamic inefficiency cannot be assessed without accounting for all the different types of land-specific investment. This paper focuses on just a single investment, albeit an important noncontractible one, the use of farmyard manure. Nevertheless, it is still instructive to ask, based on our estimates, how yields would be affected by giving land ownership rights to tenants. Fortunately, we have access to results from a large number of agricultural experiments in India compiled by Gaur (1992) showing the effect of FYM use on the yields of major crops; ${ }^{33}$ these should also be approximately valid for neighboring Pakistan. In the year of application, one metric ton of FYM per acre would increase the yields of any of the four major crops (wheat, rice, cotton, and sugarcane) by 1.5-1.75 percent. Based on the leasing coefficient from a linear model otherwise identical to specification (3) in Table 3, leased plots received on average about 0.6 metric tons less FYM per acre than owned plots in the 2000-01 agricultural year. Therefore, by converting a leased plot into an owned plot, major crop yields would rise by about one percent in the first year. Taking into account the carryover effects of FYM to future years (see fn. 9) would give a cumulative yield gain of around 2-2.5 percent. For poor tenant households in rural Pakistan, even modest gains such as these will have important income effects.

To be sure, these are just gross impacts; they do not account for the cost of FYM application, but they do give some sense of the magnitudes involved. Banerjee et al. (2002) find that a tenancy reform in India, one that fell far short of giving share-tenants full ownership rights, increased crop yields on the order of 50-60 percent. At least part of this increase, they argue, can be attributed to higher investment due to improved tenure security. Our findings suggest that investment - more precisely, noncontractible investment - may only be a small part of the story. However, we reiterate, this conclusion rests critically on what other noncontractible investments (e.g., land maintenance activities) tenants can potentially undertake and how responsive these investments are to changes in the security of tenure. Filling in these gaps in our knowledge is an important area for future research.

\footnotetext{
${ }^{33}$ These estimates are more accurate than could ever be obtained from economic data because they are quite literally taken from experiments, in which everything else is held constant. The experimental effects reported are for FYM use on top of a standard application of chemical fertilizer.
} 


\section{References}

[1] Allen, D., and D. Lueck (1993): "Transaction Costs and the Design of Cropshare Contracts," Rand Journal of Economics, 24(1):78-100.

[2] Andrews, D. (1989): "Power in Econometric Applications," Econometrica, 57(5):1059-90.

[3] Banerjee, A., P. Gertler, and M. Ghatak (2002): "Empowerment and Efficiency: Tenancy Reform in West Bengal," Journal of Political Economy, 110(2):239-280.

[4] Basu, K. (1992): "Limited Liability and the Existence of Share Tenancy," Journal of Development Economics, 38(1):203-220.

[5] Bell, C. (1977): "Alternative Theories of Sharecropping: Some Tests Using Evidence from Northeast India," Journal of Development Studies, 13(July):317-46.

[6] Besley, T. (1995): "Property Rights and Investment Incentives: Theory and Evidence from Ghana," Journal of Political Economy, 103(5):903-37.

[7] Dubois, P. (2002): "Moral hazard, Land Fertility and Sharecropping in a Rural Area of the Philippines," Journal of Development Economics, 68(1):35-64.

[8] Eswaran and Kotwal (1985): "A Theory of Contractual Structure in Agriculture," American Economic Review, 75(3):352-67.

[9] Gaur, A. C. (1992): "Bulky Organic Manures and Crop Residues," in Fertilisers, Organic Manures, Recyclable Wastes and Biofertilisers: Components of Integrated Plant Nutrition. edited by H. Tandon. New Dehli: Fertiliser Development and Consultation Organisation.

[10] Government of Pakistan (1997): Fertilizer Recommendations in Pakistan: A Pocket Guide for Extension Workers. Islamabad: Planning and Development Division.

[11] Grossman, S., and O. Hart (1986): "The Costs and Benefits of Ownership: A Theory of Vertical and Lateral Integration," Journal of Political Economy, 94(4):691-719.

[12] Hart, O. and J. Moore (1999): "Foundations of Incomplete Contracts." Review of Economic Studies, 66:115-138. 
[13] Hart, O. and J. Moore (1990): "Property Rights and the Nature of the Firm," Journal of Political Economy, 98(6):1119-58.

[14] Honore, B. (1992): "Trimmed LAD and Least Squares Estimation of Truncated and Censored Regression Models with Fixed Effects," Econometrica, 47(1): 533-65.

[15] Jacoby, H., G. Li, and S. Rozelle (2002): "Hazards of Expropriation: Tenure Security and Investment in Rural China," American Economic Review (forthcoming).

[16] Joskow, P. (1987): "Contract Duration and Relationship-Specific Investments: Empirical Evidence from Coal Markets," American Economic Review, 77(1):168-85.

[17] Jovanovic, B. (1979): "Firm-specific Capital and Turnover, Journal of Political Economy, 87(6):1246-59.

[18] Klein, B., R. Crawford, and A. Alchian (1978): "Vertical Integration, Appropriable Rents, and the Competitive Contracting Process," Journal of Law and Economics, 21(October):297-326.

[19] Kreps, D. (1990): A Course in Microeconomic Theory. Princeton, NJ: Princeton University Press.

[20] Laffont, J.-J. and M. Matoussi (1995): "Moral Hazard, Financial Constraints and Sharecropping in El Oulja," Review of Economic Studies, 62(July): 381-99.

[21] Laffont, J.-J., and D. Mortimort (2002): The Theory of Incentives: The Principal Agent Model. Princeton, NJ: Princeton University Press.

[22] Mookherjee, D. (1997): "Informational Rents and Property Rights in Land," in Property Rights, Incentives, and Welfare, edited by J. Roemer. London: Macmillan Press.

[23] North, D. and B. Weingast (1989): "Constitutions and Commitment: The Evolution of Institutions Governing Public Choice in Seventeenth Century England," Journal of Economic History, 49(Dec.):803-32.

[24] Shaban, R. (1987): "Testing between Competing Models of Sharecropping," Journal of Political Economy, 95(5):893-920.

[25] Shetty, S. (1988): "Limited Liability, Wealth Differences and Tenancy Contracts in Agrarian Economies," Journal of Development Economics, 29:1-22. 
[26] Tirole, J. (1999): "Incomplete Contracts: Where do we Stand?," Econometrica, 67:741-81.

[27] Williamson, O. (1975): Markets and Hierarchies:Analysis and Anti-trust Implications. New York: The Free Press.

[28] Wooldridge, J. (1995): "Score Diagnostics for Linear Models Estimated by Two Stage Least Squares," in Advances in Econometrics and Quantitative Economics, edited by G. S. Maddala, P. C. B. Phillips, and T. N. Srinivasan. Cambridge, MA: B. Blackwell. 
Table 1: Determinants of the Duration of Tenancy

\begin{tabular}{|c|c|c|c|}
\hline & Mean (std. dev.) & $\overline{(1)}$ & $\overline{(2)}$ \\
\hline \multicolumn{4}{|l|}{ Tenant characteristics: } \\
\hline Age & $\begin{array}{c}44.9 \\
(11.5)\end{array}$ & $\begin{array}{c}0.0021 \\
(0.0046)\end{array}$ & $\begin{array}{c}0.0021 \\
(0.0054)\end{array}$ \\
\hline Landholdings (acres) & $\begin{array}{c}2.62 \\
(10.4)\end{array}$ & $\begin{array}{l}0.0246^{*} \\
(0.0072)\end{array}$ & $\begin{array}{l}0.0412^{*} \\
(0.0163)\end{array}$ \\
\hline Own a tractor/plow & 0.22 & $\begin{array}{c}0.100 \\
(0.137)\end{array}$ & $\begin{array}{c}0.165 \\
(0.197)\end{array}$ \\
\hline Own a tubewell & 0.017 & $\begin{array}{l}-0.953 \\
(0.548)\end{array}$ & $\begin{array}{l}-0.670 \\
(0.557)\end{array}$ \\
\hline \multicolumn{4}{|l|}{ Landlord characteristics: } \\
\hline Landholdings (acres) & $\begin{array}{l}18.9 \\
(34.9)\end{array}$ & $\begin{array}{c}0.00225 \\
(0.00474)\end{array}$ & - \\
\hline Own a tractor & 0.081 & $\begin{array}{r}-0.0843 \\
(0.302)\end{array}$ & - \\
\hline Own a tubewell & 0.087 & $\begin{array}{l}-0.126 \\
(0.239)\end{array}$ & - \\
\hline $\begin{array}{l}\text { Landlord is related } \\
\text { to tenant }\end{array}$ & 0.351 & $\begin{array}{l}-0.357^{*} \\
(0.118)\end{array}$ & $\begin{array}{l}-0.672^{*} \\
(0.201)\end{array}$ \\
\hline Plot characteristics: $p$-value & & 0.0002 & 0.1947 \\
\hline Landlord fixed effects & & No & Yes \\
\hline Adjusted $R^{2}$ & & 0.2253 & 0.6491 \\
\hline
\end{tabular}


Table 2: Samples and Descriptive Statistics on Input Use

\begin{tabular}{lcccc}
\hline \hline \multicolumn{1}{c}{ Sample } & $N$ & FYM & Nitrogen & Phosphate \\
\hline Plots of multi- & 1508 & 1173 & 38.7 & 15.8 \\
plot households & & $(3048)$ & $(35.6)$ & $(20.6)$ \\
& & {$[36.7]$} & {$[85.5]$} & {$[67.6]$} \\
Plots of owner- & 477 & 1069 & 42.6 & 16.7 \\
cum-tenants & & $(2721)$ & $(38.5)$ & $(20.5)$ \\
& & {$[37.1]$} & {$[87.9]$} & {$[73.0]$} \\
Of these plots: & & & & \\
Owned & 251 & 1388 & 43.1 & 17.1 \\
& & $(3083)$ & $(39.8)$ & $(23.0)$ \\
& & {$[46.2]$} & {$[87.3]$} & {$[71.8]$} \\
Leased & 226 & 714 & 41.9 & 16.4 \\
& & $(2204)$ & $(37.1)$ & $(17.4)$ \\
Of these plots: & & {$[26.7]$} & {$[88.5]$} & {$[74.3]$} \\
Sharecropped & 127 & 702 & 32.7 & 12.9 \\
& & $(2425)$ & $(32.0)$ & $(15.2)$ \\
& & {$[29.9]$} & {$[83.5]$} & {$[67.7]$} \\
& & & \\
Fixed rental & 99 & 730 & 53.7 & 20.7 \\
& & $(1895)$ & $(39.8)$ & $(19.1)$ \\
& & {$[23.2]$} & {$[95.0]$} & {$[82.8]$} \\
\hline
\end{tabular}

Notes: Mean (std. dev.) [\% nonzero]. All quantities in kilogram per cultivated acre. 
Table 3: Household Fixed Effects Estimates of Plot-Level FYM Use

\begin{tabular}{|c|c|c|c|c|c|}
\hline & Leased & $\begin{array}{l}\text { Leased on } \\
\text { fixed rent }\end{array}$ & $\begin{array}{c}\text { Leased } \times \\
\log (\text { duration })\end{array}$ & $\eta$ & $\begin{array}{c}\text { Overidentification } \\
\text { test ( } p \text {-value) }\end{array}$ \\
\hline (1) & $\begin{array}{c}-1.98^{*} \\
(0.342)\end{array}$ & - & - & $\begin{array}{l}7 \\
0 \\
-\end{array}$ & - \\
\hline$(2)^{\mathrm{a}}$ & $\begin{array}{c}-2.47^{*} \\
(0.381)\end{array}$ & - & - & - & - \\
\hline (3) & $\begin{array}{l}-1.95^{*} \\
(0.329)\end{array}$ & - & - & $\begin{array}{l}0.152^{*} \\
(0.040)\end{array}$ & - \\
\hline$(4)^{b}$ & $\begin{array}{l}-2.15^{*} \\
(0.446)\end{array}$ & - & - & $\begin{array}{l}0.152^{*} \\
(0.040)\end{array}$ & 0.556 \\
\hline$(5)^{\mathrm{c}}$ & $\begin{array}{l}-1.65^{*} \\
(0.341)\end{array}$ & - & - & $\begin{array}{l}0.179^{*} \\
(0.040)\end{array}$ & - \\
\hline (6) & $\begin{array}{l}-1.76^{*} \\
(0.333)\end{array}$ & - & $\begin{array}{l}0.684^{*} \\
(0.216)\end{array}$ & $\begin{array}{l}0.153^{*} \\
(0.040)\end{array}$ & - \\
\hline$(7)^{b}$ & $\begin{array}{l}-1.91^{*} \\
(0.426)\end{array}$ & - & $\begin{array}{l}0.687^{*} \\
(0.221)\end{array}$ & $\begin{array}{l}0.153^{*} \\
(0.039)\end{array}$ & 0.573 \\
\hline (8) & $\begin{array}{l}-1.15^{*} \\
(0.426)\end{array}$ & $\begin{array}{l}-1.35^{*} \\
(0.587)\end{array}$ & $\begin{array}{l}0.595^{*} \\
(0.219)\end{array}$ & $\begin{array}{l}0.159^{*} \\
(0.039)\end{array}$ & - \\
\hline$(9)^{d}$ & $\begin{array}{l}-1.41^{*} \\
(0.620)\end{array}$ & $\begin{array}{l}-1.29 \\
(1.06)\end{array}$ & $\begin{array}{l}0.592^{*} \\
(0.232)\end{array}$ & $\begin{array}{l}0.160^{*} \\
(0.039)\end{array}$ & 0.208 \\
\hline$(10)^{a}$ & $\begin{array}{c}-1.84^{*} \\
(0.579)\end{array}$ & $\begin{array}{l}-0.844 \\
(0.819) \\
\end{array}$ & $\begin{array}{c}1.15^{*} \\
(0.287)\end{array}$ & - & - \\
\hline
\end{tabular}

Notes: Standard errors in parentheses $(*$ denotes p-value $<0.05)$. The dependent variable is $\log (\mathrm{kg}$ FYM per acre + 0.1). All specifications include 12 plot characteristics (see Table A.1).

${ }^{\mathbf{a}}$ Fixed effect tobit with quadratic loss function. Coefficient and s.e. multiplied by 1 - censoring rate.

${ }^{\mathbf{b}}$ IV estimates. Sig. test of excluded IVs in first-stage leasing equation: $F(12,891)=89.6$

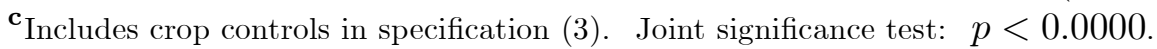

$\mathbf{d}_{\mathrm{IV}}$ estimates. Sig. test of excluded IVs in first-stage leasing equation, $F(18,885)=60.6$, for leasing on fixed rent, $F(18,885)=27.3$. 
Table 4: Household Fixed Effects Estimates of Plot-Level Chemical Fertilizer Use

\begin{tabular}{lccc}
\hline \hline & Leased & Leased on fixed rent & $\begin{array}{c}\text { Leased } \times \\
\log (\text { duration })\end{array}$ \\
\hline Nitrogen & & & \\
$\mathbf{( 1 )}$ & -0.340 & -0.038 & -0.029 \\
& $(0.311)$ & $(0.430$ & $(0.156)$ \\
$(\mathbf{2})^{\mathbf{a}}$ & -0.487 & -0.080 & -0.039 \\
& $(0.327)$ & $(0.468)$ & $(0.191)$ \\
$\mathbf{( 3 )}$ & -0.765 & 0.332 & -0.067 \\
$\mathbf{P h o s p h a t e}$ & $(0.479)$ & $(0.927)$ & $(0.170)$ \\
\hline $\mathbf{4})$ & 0.187 & -0.516 & 0.181 \\
& $(0.400)$ & $(0.553)$ & $(0.200)$ \\
$(\mathbf{5})^{\mathbf{a}}$ & 0.104 & -0.528 & 0.185 \\
& $(0.484)$ & $(0.524)$ & $(0.205)$ \\
\hline
\end{tabular}

Notes: Standard errors in parentheses (* denotes p-value $<0.05)$. The dependent variable is

$\log (\mathrm{kg}$ fertilizer per acre +0.01$)$. All specifications include 12 plot characteristics (see Table A.1).

${ }^{a}$ Fixed effect tobit with quadratic loss function. Coefficient and s.e. multiplied by 1 - censoring rate.

${ }^{\mathbf{b}}$ IV estimates. Sig. test of excluded IVs in first-stage leasing equation, $F(10,895)=87.5$,

for leasing on fixed rent, $F(10,895)=27.2$. Overidentification test p-value $=0.299$. 


\section{Appendix}

Table A.1: Descriptive Statistics and Results for Plot Characteristics

\begin{tabular}{|c|c|c|c|c|}
\hline & "Mean (std. dev.) & $\overline{\text { FYM }}$ & Nitrogen & Phosphate \\
\hline $\log ($ total area $)$ & $\begin{array}{c}3.31 \\
(1.18)\end{array}$ & $\begin{array}{c}0.427^{*} \\
(0.172)\end{array}$ & $\begin{array}{l}0.335^{*} \\
(0.123)\end{array}$ & $\begin{array}{l}0.817^{*} \\
(0.159)\end{array}$ \\
\hline Outside village & 0.078 & $\begin{array}{l}-1.56^{*} \\
(0.51)\end{array}$ & $\begin{array}{l}-0.180 \\
(0.380)\end{array}$ & $\begin{array}{l}-1.11^{*} \\
(0.489)\end{array}$ \\
\hline Flat topography & 0.83 & $\begin{array}{c}0.620 \\
(0.485)\end{array}$ & $\begin{array}{c}-0.258 \\
(0.353)\end{array}$ & $\begin{array}{l}-0.009 \\
(0.454)\end{array}$ \\
\hline $\log ($ value per acre $)$ & $\begin{array}{c}9.47 \\
(1.03)\end{array}$ & $\begin{array}{c}0.699^{*} \\
(0.332)\end{array}$ & $\begin{array}{c}0.251 \\
(0.231)\end{array}$ & $\begin{array}{c}0.498 \\
(0.297)\end{array}$ \\
\hline \multicolumn{5}{|l|}{ Access to canal irrigation: } \\
\hline Perennial & 0.309 & $\begin{array}{l}2.42^{*} \\
(1.02)\end{array}$ & $\begin{array}{c}0.531 \\
(0.730)\end{array}$ & $\begin{array}{c}0.516 \\
(0.939)\end{array}$ \\
\hline Seasonal & 0.204 & $\begin{array}{l}2.22^{*} \\
(0.96)\end{array}$ & $\begin{array}{l}-0.684 \\
(0.677)\end{array}$ & $\begin{array}{c}-0.494 \\
(0.871)\end{array}$ \\
\hline \multicolumn{5}{|l|}{ Access to groundwater: } \\
\hline Yes, good quality & 0.381 & $\begin{array}{c}2.52^{*} \\
(0.854)\end{array}$ & $\begin{array}{l}-0.170 \\
(0.619)\end{array}$ & $\begin{array}{c}0.216 \\
(0.797)\end{array}$ \\
\hline Yes, somewhat brackish & 0.054 & $\begin{array}{l}0.402 \\
(1.40)\end{array}$ & $\begin{array}{c}1.15 \\
(1.00)\end{array}$ & $\begin{array}{l}0.374 \\
(1.29)\end{array}$ \\
\hline Yes, very brackish & 0.048 & $\begin{array}{l}-1.30 \\
(2.03)\end{array}$ & $\begin{array}{c}1.51 \\
(1.51)\end{array}$ & $\begin{array}{c}2.71 \\
(1.95)\end{array}$ \\
\hline \multicolumn{5}{|l|}{ Soil type: } \\
\hline Sandy & 0.197 & $\begin{array}{c}-1.42^{*} \\
(0.656)\end{array}$ & $\begin{array}{l}-0.692 \\
(0.467)\end{array}$ & $\begin{array}{l}-0.026 \\
(0.601)\end{array}$ \\
\hline Maira & 0.275 & $\begin{array}{c}-0.666 \\
(0.736)\end{array}$ & $\begin{array}{l}-0.572 \\
(0.531)\end{array}$ & $\begin{array}{l}-0.052 \\
(0.684)\end{array}$ \\
\hline Chikni & 0.235 & $\begin{array}{c}-0.535 \\
(0.772) \\
\end{array}$ & $\begin{array}{l}-1.21^{*} \\
(0.560) \\
\end{array}$ & $\begin{array}{c}0.155 \\
(0.721) \\
\end{array}$ \\
\hline$p$-value & & 0.0000 & 0.0571 & 0.0003 \\
\hline
\end{tabular}

